\title{
Achieving complete reaction while the solid volume increases: a numerical model applied to serpentinisation
}

\author{
Benjamin Malvoisin ${ }^{\mathrm{a}, \mathrm{b}, *}$, Yury Y. Podladchikov ${ }^{\mathrm{b}, \mathrm{c}}$, Artem V. Myasnikov ${ }^{\mathrm{c}}$ \\ ${ }^{a}$ Univ. Grenoble Alpes, Univ. Savoie Mont Blanc, CNRS, IRD, IFSTTAR, ISTerre, 38000 \\ Grenoble, France \\ ${ }^{b} I S T E-F G S E$, Université de Lausanne, Quartier de la Mouline, Géopolis, CH-1015 \\ Lausanne, Switzerland \\ ${ }^{c}$ Faculty of Mechanics and Mathematics, Moscow State University, Russian Federation
}

\begin{abstract}
Solid volume increases during the hydration of mantle rocks. The fluid pathways necessary to feed the reaction front with water can be filled by the low density reaction products. As a result, the reaction front dries out and the reaction stops at low reaction progress. This process of porosity clogging is generally predicted to dominate in reactive transport models, even when processes such as reaction-induced fracturing are considered. These predictions are not consistent with observations at mid-ocean ridges where dense mantle rocks can be completely replaced by low density serpentine minerals. To solve this issue, we develop a numerical model coupling reaction, fluid flow and deformation. High extents of reaction can only be achieved when considering that the increase in solid volume during reaction is accommodated through deformation rather than porosity clogging. The model can generate an overpressure that depends on the extent of reaction and on the boundary conditions. This overpressure induces viscoelastic compaction that limits the extent of the reaction. The serpentinisation rate is therefore controlled by the accommodation of volume change during reaction, and thus by deformation, either induced by the reaction itself or by tectonic processes.
\end{abstract}

Keywords: serpentinisation, numerical model, reaction rate, tectonic deformation, solid volume increase, fluid pathways, porosity clogging, crystallisation pressure.

\section{Introduction}

Olivine, the main component of mantle peridotites, hydrates at temperature below $\sim 400{ }^{\circ} \mathrm{C}$ to form serpentine \pm brucite \pm magnetite \pm hydrogen Evans, 1977). This so-called reaction of serpentinisation requires fluid transport along 5 pathways often formed by tectonic deformation. In marine geodynamic settings,

*Corresponding author: benjamin.malvoisin@univ-grenoble-alpes.fr 
the fluid pathways include detachment faults at slow-spreading mid-ocean ridges (Cannat, 1993, Escartín et al., 2008; Rüpke and Hasenclever, 2017), bend-faults at ocean trenches (Ranero et al., 2003: Van Avendonk et al., 2011), and extensional faults at passive margins (Bayrakci et al., 2016). Here we focus on 10 serpentinisation during mantle rock exhumation in the footwall of detachment faults at slow spreading mid-ocean ridges.

Serpentinisation induces changes in the behaviour of the oceanic lithosphere due to strong differences in the physico-chemical properties of the reactants and the products. Serpentine content above $\sim 10 \%$ reduces the rock strength by 15 decreasing the friction coefficient from 0.6 to $\sim 0.4$ (Escartín et al., 1997) with consequences on the rheology of the detachment faults active at mid-ocean ridges (Bickert et al., 2020). Magnetite is a ferrimagnetic mineral with a magnetisation four orders of magnitudes higher than olivine (Malvoisin et al. 2012b). Its precipitation during serpentinisation can generate magnetic anomalies on the 20 seafloor (Szitkar et al. 2014). Hydrogen is an energy source for chemosynthetic organisms and participates in the abiotic synthesis of organic compounds possibly involved in the origin of life (Russell et al., 2010, McCollom and Seewald, 2013). Serpentinisation is also an exothermic reaction possibly modifying the heat budget at mid-ocean ridges (Macdonald and Fyfe, 1985). Predicting the

25 evolution of the oceanic lithosphere thus requires to model the rate and the extent of serpentinisation at mid-ocean rdiges.

Serpentinisation is already modelled at the kilometre scale to investigate its influence on hydrothermal circulation, heat budget and geodynamics (Emmanuel and Berkowitz, 2006; Delescluse and Chamot-Rooke, 2008; Iyer et al.,

30 2010 Bickert et al. 2020). Reaction rate is assumed to be controlled by a single process in these models. Emmanuel and Berkowitz (2006) and Iyer et al. (2010) used a law derived from experiments of olivine powder hydration (Martin and Fyfe, 1970) whereas Bickert et al. (2020) relate serpentinisation rate to the shear deformation. It remains unclear which assumption should be pre-

35 ferred to model serpentinisation at large scale. Moreover, the used models are either incompressible, considering a constant porosity or using a parametrized law for the evolution of porosity. Such approaches are justified by the need to use simplifying assumptions when modelling processes at different time and space scales. However, they cannot take into account the impact of hydration 40 on density and porosity whereas these parameters strongly modify deformation and fluid flow.

Volume change during reaction is the key parameter for modelling the couplings between reaction, deformation and fluid flow. Serpentinisation induces a change in solid volume $(\Delta V / V)$ of $\sim 50 \%$ in a closed system (Macdonald

45 and Fyfe, 1985: O'Hanley, 1992). Mass transfer through aqueous species transport can reduce the increase in solid volume (Thayer, 1966: Carmichael, 1987, Fletcher and Merino, 2001). However, Malvoisin et al. (2020b) and Klein and Le $\operatorname{Roux}(2020)$ measure $\Delta V / V$ in natural samples and in experiments close to the theoretical value for reaction in a closed system, suggesting that mass transfer is ${ }_{50}$ limited, at least during the incipient stage of the reaction. The serpentinisation rate directly depends on the evolution of the fluid pathways during reaction. 
They initially form by thermal cracking (Demartin et al., 2004; Boudier et al., 2010) or tectonic deformation (Rouméjon et al., 2015), and then evolve during reaction as a consequence of $\Delta \bar{V} / V$. The precipitation of reaction products in 55 the pores reduces the permeability by several orders of magnitude (Godard et al., 2013 Farough et al. 2015). However, a porosity is observed at the nanoscale in serpentinized peridotites (Tutolo et al., 2016). Fluid pathways could thus be preserved during reaction, even though this should be confirmed with the acquisition of data on pore connectivity at the nanoscale. The positive change

60 in volume during reaction also generates stresses (i.e. crystallisation pressure) sufficient to fracture the rock (Jamtveit et al., 2009 Kelemen and Hirth, 2012 , Plümper et al., 2012, Malvoisin et al., 2017).

The positive $\Delta V / V$ is considered in some models of serpentinisation. It induces stress build-up and crack generation in the models of reaction-induced 65 fracturing (Rudge et al., 2010, Ulven et al., 2014, Shimizu and Okamoto, 2016 Malvoisin et al., 2017; Zhang et al., 2019). These models predict an increase in reactive surface area during reaction and reproduce the mesh microtexture observed in natural samples. However, they either do not take into account Darcian flow, or they do not conserve fluid mass, and are consequently not able 70 to quantitatively model porosity evolution during reaction (Evans et al., 2020). Reactive transport models such as TOUGHREACT (Xu et al. 2011) incorporate the volumetric effect of reaction on transport properties. They predict a strong reduction in porosity during reaction inducing a positive $\Delta V / V$, preventing the achievement of the high extents of reaction measured in natural samples

75 (Liu et al. 2019, Marini, 2007). This limitation probably arises from the omission in these models of mechanisms responsible for fluid pathways generation or preservation. Evans et al. (2020) consider reaction-induced fracturing in a model combining reaction and fluid flow. They were able to model the effect on fluid pathway evolution of the competition between cracking and porosity

80 clogging. However, high extents of reaction $(>60 \%)$ are only achieved in the cracks with limited hydration in the rock groundmass. The main issue regarding serpentinisation modelling thus consists in being able to predict the high extents of reaction observed in the natural samples.

The present contribution aims at proposing a new model of serpentinisation 85 addressing this issue. We derive a new set of equations to model the couplings between reaction, deformation and fluid flow. Based on observations in natural samples, we consider that the solid volume increase is accommodated through deformation rather than porosity clogging. The new model is applied to serpentinisation at mid-ocean ridges in the footwall of a detachment fault. We model 9o fluid-rock interaction during hydrothermal circulation with a one-dimensional numerical model. The impact of the parameter values on the model predictions is explored. On the contrary to previous modelling attempts, the new approach allows high extents of reaction to be reached and reaction-induced pressure increase to be predicted. The model is finally used to discuss the processes 95 controlling the serpentinisation rate. 


\section{Modelling the couplings between reaction, deformation and fluid flow}

The model considers a porous matrix of dunite reacting with water in the stability field of serpentine + brucite. Serpentinisation is assumed to be isochemical except for the addition of water based on the study of Malvoisin et al. (2020b). Si, $\mathrm{Mg}$ and $\mathrm{Fe}$ are thus not transported as aqueous species between the model grid points. We use here a two-phase continuum medium approach by defining macroscopic properties such as porosity and extent of reaction for a mineralogical assemblage potentially composed at each grid point of both olivine and its reaction products. This approach is valid at a scale larger than the olivine grain size so that the rock properties can be averaged over a significant number of grains. Olivine grains reacting during serpentinisation have a typical size of $100 \mu \mathrm{m}$ (Malvoisin et al., 2017). The model can thus be used from a scale of $\sim 1 \mathrm{~mm}$. The model parameters and their values are given in

${ }_{110}$ Table 1. The model is based on the model developed in Malvoisin et al. (2015) and in Omlin et al. (2017). The thermodynamic admissibility of the systems of equations derived below is also verified following the procedure described in Yarushina and Podladchikov (2015) (see supplementary materials for details).

The mass conservation equations can be written for the total system as:

$$
\frac{\partial\left(\rho_{w} \phi+\rho_{s}(1-\phi)\right)}{\partial t}+\nabla_{j}\left(\rho_{w} \phi v_{w}^{j}+\rho_{s}(1-\phi) v_{s}^{j}\right)=0
$$

115

and for the dry solid as:

$$
\frac{\partial\left(\rho_{s}\left(1-X_{s}\right)(1-\phi)\right)}{\partial t}+\nabla_{j}\left(\rho_{s}\left(1-X_{s}\right)(1-\phi) v_{s}^{j}\right)=0
$$

where $X_{s}, \phi, \rho, v^{j}$ and $\nabla_{j}$ are the mass fraction of water bound to the solid, the porosity, the density, the $j$ components of the velocity vector and the $\mathrm{j}$ components of the del operator, respectively. The solid properties are denoted with a subscript $s$, and the water properties are denoted with a subscript $w$. This particular choice of two independent mass conservation equations is motivated by their independence on (de)hydration reactions and the absence of reactionrelated source terms.

The conservation of fluid momentum is modelled with the Darcy's law:

$$
\phi\left(v_{w}^{j}-v_{s}^{j}\right)=-\frac{k_{\phi}}{\eta_{w}}\left(\nabla_{j} P_{w}+\rho_{w} g e_{z}^{j}\right)
$$

125

where $k_{\phi}$ is the permeability, $\eta_{w}$ is the fluid viscosity, $P_{w}$ is the fluid pressure and $e_{z}^{j}$ are the components of an upward directed unit vector. Combining equation 3 with equations 1 and 2 allows water velocity to be eliminated.

The changes in density are modelled by introducing compressibilities. The solid compressibility and the density change during reaction contribute to the 


\begin{tabular}{|c|c|c|c|}
\hline Symbol & Definition & Unit & Value \\
\hline 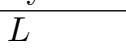 & Length of the numerical model & $m$ & $10^{-1}-10^{2}$ \\
\hline$\rho_{w}$ & Water density & $k g \cdot m^{-3}$ & 1000 (at $200^{\circ} \mathrm{C}$ and $50 \mathrm{MPa}$ ) \\
\hline$\rho_{s}$ & Solid density & kg. $m^{-3}$ & 3300 (initial value) \\
\hline$v_{w}^{j}$ & Velocity of water & $m . s^{-1}$ & \\
\hline$v_{s}^{j}$ & Velocity of the solid & $m . s^{-1}$ & \\
\hline$\stackrel{s}{X_{s}}$ & Mass fraction of water bound in the solid & None & 0 (initial value) \\
\hline$X_{s e q}$ & $\begin{array}{l}\text { Mass fraction of water bound in the solid at } \\
\text { the equilibrium }\end{array}$ & None & $0.126^{\star}$ \\
\hline$\phi$ & Porosity & None & \\
\hline$\phi_{0}$ & Initial porosity & None & 0.01 \\
\hline$\phi_{p}$ & $\begin{array}{l}\text { Porosity above which a porous rock has the } \\
\text { same reactive surface area as a powder }\end{array}$ & None & 0.38 \\
\hline$k_{\phi}$ & Permeability & $m^{2}$ & $10^{-20}-10^{-16}$ \\
\hline$\eta_{w}$ & Water viscosity & Pa.s & $10^{-4}$ \\
\hline$g$ & Gravity acceleration & $m^{2} \cdot s^{-1}$ & 9.81 \\
\hline$e_{z}^{j}$ & Unit vector along upward directed z-axis & None & \\
\hline$\eta_{\phi}$ & Pore viscosity & Pa.s & $10^{17}-10^{20}$ \\
\hline$\tau$ & Characteristic time for reaction & $s$ & $10^{7}-10^{9}$ \\
\hline$P_{w}$ & Fluid pressure & $\mathrm{Pa}$ & $50.10^{6}$ (initial value) \\
\hline$P_{s}$ & Solid pressure & $\mathrm{Pa}$ & $50.10^{6}$ (initial value) \\
\hline $\bar{P}$ & Total pressure (fluid + solid) & $\mathrm{Pa}$ & $50.10^{6}$ (initial value) \\
\hline$\beta_{d}$ & Drained compressibility & $P a^{-1}$ & $7.10^{-10}$ \\
\hline$\beta_{s}^{\prime}$ & $\begin{array}{l}\text { Solid compressibility measured in an unjack- } \\
\text { eted test }\end{array}$ & $P a^{-1}$ & $1.5 .10^{-11}$ \\
\hline$\beta_{w}$ & Fluid compressibility defined in equation 6 & $P a^{-1}$ & $10^{-9 \star}$ \\
\hline$\beta_{e f}$ & Effective compressibility in front of $P_{w}$ & $P a^{-1}$ & \\
\hline$\beta_{e t}$ & Effective compressibility in front of $\bar{P}$ & $P a^{-1}$ & \\
\hline$\beta_{s r}$ & $\begin{array}{l}\text { Change in solid density due to reaction (de- } \\
\text { fined in equation 4) }\end{array}$ & None & $1.7^{\star}$ \\
\hline$\dot{\epsilon}_{V}$ & Dilatational strain rate & $s^{-1}$ & $10^{-14}-10^{-9}$ \\
\hline$\xi$ & Extent of reaction $\left(\xi=\frac{X_{s}}{X_{s e q}}\right)$ & None & $0-1$ \\
\hline$\dot{\xi}$ & Serpentinisation rate & $s^{-1}$ & \\
\hline$t_{80}$ & Time to reach $80 \%$ of extent of reaction & $s$ & \\
\hline
\end{tabular}

Table 1: Symbols used in the mathematical model. *: parameter value calculated with Perple_X (Connolly, 2005 
solid density evolution:

$$
\frac{1}{\rho_{s}} \frac{d \rho_{s}}{d t}=\beta_{s}^{\prime}\left(\frac{d P_{s}}{d t}-\frac{\bar{P}-P_{w}}{(1-\phi)^{2}} \frac{d \phi}{d t}\right)-\beta_{s r} \frac{1}{1-X_{s}} \frac{d X_{s}}{d t}
$$

where $\beta_{s}^{\prime}$ is the solid compressibility measured in an unjacketed test, $\beta_{s r}$ is the density change associated with hydration $\left(X_{s}\right.$ modification), and $P_{s}$ is the solid pressure. $\frac{d}{d t}$ is the material derivative of the solid phase defined as $\frac{d}{d t}=\frac{\partial}{\partial t}+v_{s}^{j} \nabla_{j} . P_{s}$ is combined with $P_{w}$ to calculate the total pressure $(\bar{P})$ as:

$$
\bar{P}=\phi P_{w}+(1-\phi) P_{s}
$$

The change in fluid density is calculated by introducing the fluid compressibility $\left(\beta_{w}\right)$ :

$$
\frac{1}{\rho_{w}} \frac{d_{w} \rho_{w}}{d t}=\beta_{w} \frac{d_{w} P_{w}}{d t}
$$

where $\frac{d_{w}}{d t}$ is the material derivative of the water defined as $\frac{d_{w}}{d t}=\frac{\partial}{\partial t}+v_{w}^{j} \nabla_{j}$ Finally, the change in composition $\left(X_{s}\right)$ is modelled with a first-order kinetic law:

$$
\frac{d X_{s}}{d t}=\left(\frac{\phi}{\phi_{p}}\right)^{2 / 3} \frac{X_{s e q}-X_{s}}{\tau}
$$

where $\tau$ is the characteristic time for reaction and $X_{s e q}$ is the water mass fraction bound to the solid at the equilibrium, that is in the serpentine + brucite assemblage. The evolution of reactive surface area during reaction is modelled as a function of porosity with the geometrical relationship proposed by Lichtner (1988) and Kieffer et al. (1999). $\phi_{p}$ is the minimum porosity for which a porous rock has the same reactive surface area than a powder. We use a value of 0.38 in the following based on the experimental results of Llana-Fúnez et al. (2007).

Equations 1, 2, 3, 4, 6, 5 and 7 form a system of nine equations in thirteen unknowns, 7 scalars $\left(\rho_{w}, \rho_{s}, \phi, X_{s}, P_{w}, P_{s}\right.$ and $\left.\bar{P}\right)$ and 6 vector components $\left(v_{w}^{j}\right.$ and $\left.v_{s}^{j}\right)$. Solving this system of equations thus requires four additional equations.

The conservation of total momentum could first be used (Malvoisin et al. 2015 ) but this would require to solve for shear stress evolution which is beyond the scope of this study. We thus explore the behaviour of the system of equations for two cases: (i) a constant solid volume $\left(\nabla_{j} v_{s}^{j}=0\right)$; (ii) a constant total pressure $(\bar{P}=$ constant $)$. These approximations correspond to idealized systems in which reaction-induced change in volume is either not accommodated (i) or fully accommodated (ii) by deformation. The behaviour of a real system is expected to be intermediate between these two extreme cases. Nevertheless, these approximations provide maximum estimates for total pressure variation during reaction (i) and reaction-induced deformation (ii).

The last equation necessary to close the system of equations is the equation for solid deformation. We show below why this equation plays a key role for 
modelling solid volume change during reaction. We first present the classical form of this equation usually used in reactive transport models. We then show how it should be modified to take into account observations at the nanoscale of limited mass transfer during serpentinisation.

\subsection{Classical approach}

The classical approach refers here to models in which reaction-induced deformation is not considered in the equations for solid deformation. This approach

170 is used in most of the models considering the couplings between reaction and deformation(Balashov and Yardley, 1998, Xu et al., 2011, Tian and Ague, 2014. Malvoisin et al., 2015; Tian et al., 2018, Malvoisin et al., 2020a; Evans et al. 2020 Schmalholz et al. 2020). With the classical approach, solid deformation is modelled independently from reaction for example with a visco-elastic rheology (Yarushina and Podladchikov, 2015):

$$
\nabla_{j} v_{s}^{j}=-\beta_{d} \frac{d \bar{P}}{d t}+\left(\beta_{d}-\beta_{s}^{\prime}\right) \frac{d P_{w}}{d t}-\frac{\bar{P}-P_{w}}{(1-\phi) \eta_{\phi}}
$$

where $\beta_{d}$ and $\eta_{\phi}$ are respectively, the drained compressibility and the pore viscosity.

Re-arranging equations 1, 2, 3, 4, 5, 6, and 7, with additional equation 8 provides a closed system of three equations describing the system evolution with three unknown scalar functions, porosity $(\phi)$, fluid pressure $\left(P_{w}\right)$ and mass fraction of water in the solid $\left(X_{s}\right)$ :

$$
\left\{\begin{aligned}
\frac{d X_{s}}{d t} & =\left(\frac{\phi}{\phi_{p}}\right)^{2 / 3} \frac{X_{s e q}-X_{s}}{\tau} \\
\nabla_{j} \frac{k_{\phi}}{\eta_{w}}\left(\nabla_{j} P_{w}+\rho_{w} g e_{z}^{j}\right) & =-\beta_{e_{t}} \frac{d \bar{P}}{d t}+\beta_{e_{w}} \frac{d P_{w}}{d t}-\frac{\bar{P}-P_{w}}{(1-\phi) \eta_{\phi}}+\left(\frac{\rho_{s}}{\rho_{w}}-\left(1+\beta_{s r}\right)\right) \frac{1-\phi}{1-X_{s}} \frac{d X_{s}}{d t} \\
\frac{1}{(1-\phi)} \frac{d \phi}{d t} & =\left(\beta_{e_{t}}-\frac{\beta_{s}^{\prime} \phi}{1-\phi}\right)\left(-\frac{d \bar{P}}{d t}+\frac{d P_{w}}{d t}\right)-\frac{\bar{P}-P_{w}}{(1-\phi) \eta_{\phi}}-\frac{1+\beta_{s r}}{1-X_{s}} \frac{d X_{s}}{d t}
\end{aligned}\right.
$$

where $\beta_{e_{t}}$ and $\beta_{e_{w}}$ are the total and fluid effective compressibilities, respectively, defined as

$$
\beta_{e_{t}}=\beta_{d}-\beta_{s}^{\prime},
$$

and

$$
\beta_{e_{w}}=\beta_{e_{t}}+\phi\left(\beta_{w}-\beta_{s}^{\prime}\right) .
$$

Reactive terms appear in the fluid pressure and the porosity evolution equations in 9 . This implies that volume change during reaction is accommodated through precipitation in the pores and fluid pressure variation. Mineralogical reactions in the presence of fluid proceed through four steps: the transport of fluid up to the primary minerals, the dissolution of the primary minerals, the transport of aqueous species and the precipitation of the secondary minerals 

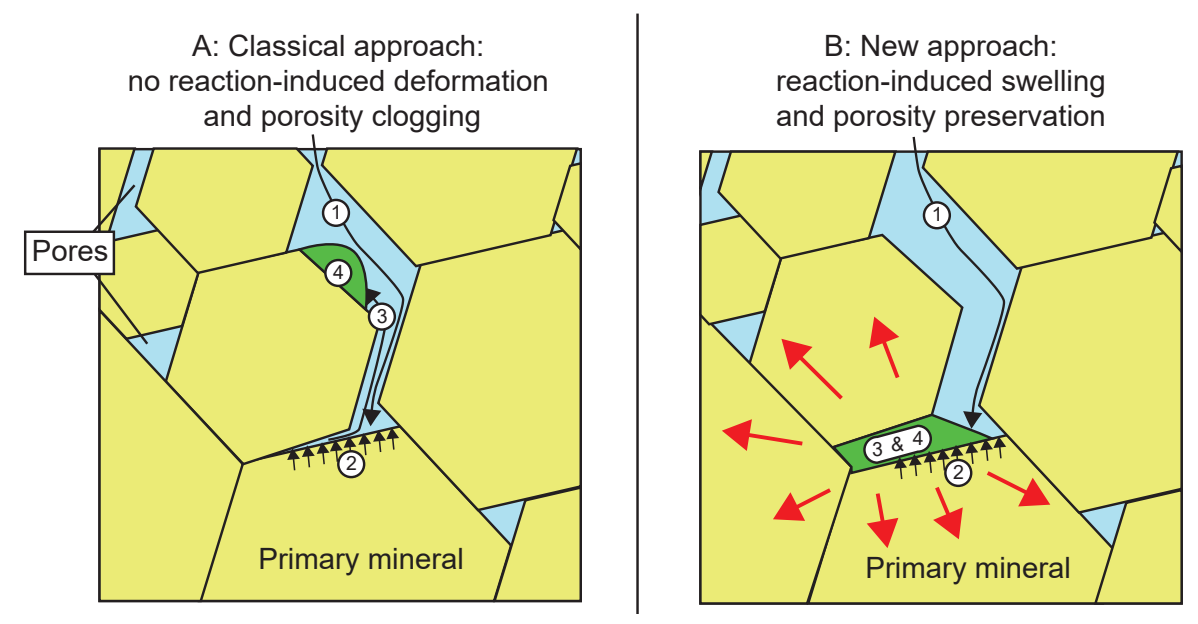

Figure 1: The two types of models to link reaction, porosity evolution and solid deformation. Mineralogical reactions in the presence of fluid can be decomposed in four steps: fluid transport in the pore network (1); primary mineral (in yellow) dissolution (2); aqueous species transport (3); and secondary phase (in green) precipitation (4). A: the classical approach consists in considering that aqueous species are transported up to the pores where precipitation occurs. This process does not generate deformation directly. B: the new approach proposed here is based on observations at the nanoscale showing that aqueous species transport can be limited to a scale of less than $100 \mathrm{~nm}$. As a result, the reaction products do not precipitate in the pores but at the surface of the primary mineral. This implies that reaction induces rock deformation (i.e. swelling; red arrows).

(Figure 1). Modelling fluid-mediated reactions thus requires to assume that aqueous species transport occurs. We do not consider this process in our equations, implying that the occurrence of aqueous species transport is restricted to a scale below the spacing of the grid points in our model $(<1 \mathrm{~mm})$. However, we directly relate here porosity evolution to reaction. This implicitly requires that mass transfer efficiently occurs at least at the micrometer scale from the olivine surface up to the pores (Figure 1A). This latter assumption may not be verified during hydration reactions as suggested by observations in natural samples (Beard et al., 2009, Boudier et al., 2010, Malvoisin et al., 2020b). We propose in the following a way to take into account these observations by modifying equation 8 .

\subsection{A new approach: reaction-induced swelling}

At the submicrometre scale, Beard et al. (2009) and Malvoisin et al. (2020b) report reaction products dominated by a serpentine + brucite mixture with a composition similar to olivine except for the addition of water. Boudier et al. (2010) show the presence of a $\sim 100 \mathrm{~nm}$ thick zone coating the olivine surface, and composed of pre-hydrated olivine. Serpentinisation is thus isochemical at least at the hundred of nanometre scale with limited aqueous species transport, probably by diffusion at grain boundaries (Tutolo et al. 2016) (Figure1B). Such 
a replacement process with limited transport is not expected to significantly modify the existing pores. This implies that the positive change in solid volume occurring during reaction is not accommodated by mass transfer up to the pores but rather by deformation (Figure $1 \mathrm{~B}$ ). All these observations can be taken into account by modifying equation 8 such that porosity evolution does not depend on volume change during reaction:

$$
\nabla_{j} v_{s}^{j}=-\beta_{d} \frac{d \bar{P}}{d t}+\left(\beta_{d}-\beta_{s}^{\prime}\right) \frac{d P_{w}}{d t}-\frac{\bar{P}-P_{w}}{(1-\phi) \eta_{\phi}}+\frac{1+\beta_{s r}}{1-X_{s}} \frac{d X_{s}}{d t}
$$

The last term in equation 12 is the deformation induced by solid volume change. With this new equation for solid momentum conservation, a new closed system of three equations for three unknown functions, $\phi, P_{w}$ and $X_{s}$ is obtained by also using equations $1,2,3,4,5,6$ and 7 .

$$
\left\{\begin{aligned}
\frac{d X_{s}}{d t} & =\left(\frac{\phi}{\phi_{p}}\right)^{2 / 3} \frac{X_{s e q}-X_{s}}{\tau} \\
\nabla_{j} \frac{k_{\phi}}{\eta_{w}}\left(\nabla_{j} P_{w}+\rho_{w} g e_{z}^{j}\right) & =-\beta_{e_{t}} \frac{d \bar{P}}{d t}+\beta_{e_{w}} \frac{d P_{w}}{d t}-\frac{\bar{P}-P_{w}}{(1-\phi) \eta_{\phi}} \\
& +\left(\frac{\rho_{s}(1-\phi)}{\rho_{w}}+\phi\left(1+\beta_{s r}\right)\right) \frac{1}{1-X_{s}} \frac{d X_{s}}{d t} \\
\frac{1}{(1-\phi)} \frac{d \phi}{d t} & =\left(\beta_{e_{t}}-\frac{\beta_{s}^{\prime} \phi}{1-\phi}\right)\left(-\frac{d \bar{P}}{d t}+\frac{d P_{w}}{d t}\right)-\frac{P_{w}}{(1-\phi) \eta_{\phi}}
\end{aligned}\right.
$$

\subsection{Numerical methods, initial set-up and parameters}

The numerical model aims at determining the conditions necessary to reach high reaction progress during serpentinisation at mid-ocean ridges. We build a simple idealized model for fluid-rock interaction during hydrothermal circulation in exhumed mantle rocks. We do not consider shear deformation and the strong changes in rock composition occurring during extensive alteration. The model 225 thus rather applies to a region located outside the shear zones involved in exhumation in the footwall of a detachment fault . We consider a one-dimensional domain of length $L$ undergoing serpentinisation at $200^{\circ} \mathrm{C}$ and $50 \mathrm{MPa}$ (initial fluid and total pressures). We impose a constant fluid pressure of $50 \mathrm{MPa}$ at the model boundaries during simulation. The domain is assumed horizontal so that

230 gravity terms can be neglected. It is initially exclusively composed of olivine (dunite; $X_{s}=0$ ). The initial porosity is of $\phi_{0}=0.01$ to allow for fluid transport and reaction initiation. We predict the evolution of porosity, pressures and rock hydration degree with the systems of equations 9 and 13 for a wide range of model parameter values.

The numerical scheme consists in solving nondimensional versions of equations 9 and 13 with an explicit algorithm using pseudotransient iterations Kelley and Keyes (1998). This algorithm is validated for the system of equations 9 by 
reproducing an analytical solution in Omlin et al. (2017). We also produce an analytical benchmark for the system of equations 13 . The algorithm is validated for this system of equations by reproducing an analytical prediction (see the derived analytical solution in the supplementary materials). The non-dimensional equations are obtained by choosing the model scale as the length scale $(\delta=L)$, the inverse of the compressibility as the pressure scale $\left(p^{\star}=\frac{1}{\beta_{\text {efo }}}\right)$ and the characteristic time for viscous compaction as the time scale $\left(t^{\star}=\frac{\eta_{\phi}}{p^{\star}}\right)$. This 245 leads to the introduction of two nondimensional numbers describing the system behaviour : the Dahmköhler number comparing the characteristic times for viscoelastic relaxation and for reaction $\left(D a=\frac{\beta_{e f 0} \eta_{\phi}}{\tau}\right)$; the Deborah number comparing the characteristic times for viscoelastic relaxation and for viscous compaction $\left(D e=\sqrt{\frac{k_{\phi} \eta_{\phi}}{\eta_{w} L^{2}}}\right)$. The non-dimensional systems of equations solved 250 in the numerical models can be found in the supplementary materials. For clarity, we present the following results with dimensional quantities.

The values of the parameters used in the model are given in Table 1. Some parameters such as compressibility are well-constrained. $\beta_{w}$ is calculated with Perple $\mathrm{X}$ (Connolly, 2005) by computing the derivative of $\rho_{w}$ with pressure at $200^{\circ} \mathrm{C}$ and $50 \mathrm{MPa}$. We also use Perple_X to compute the change in solid density as a function of $X_{s}$ that is used to calculate $\beta_{s r}$. For the other less constrained parameters, we provide in the following ranges of possible values which are used to compute the $D a$ and $D e$ values to be used in the simulations.

Observations in natural samples reveal that preferred fluid pathways separate $10 \mathrm{~cm}$ - to $100 \mathrm{~m}$-wide domains undergoing serpentinisation (Rouméjon et al. 2015). We use this size range as the length of the model $(L)$. Permeability measured during fluid flow experiments on peridotite takes values comprised between $10^{-20}$ and $10^{-16} \mathrm{~m}^{2}$ (Godard et al., 2013; Farough et al., 2015). Pore viscosity spans over four orders of magnitude $\left(10^{17}\right.$ to $10^{20} \mathrm{~Pa} . \mathrm{s}$; (Hilairet et al., 2007)). The characteristic time for dunite serpentinisation are calculated for an initial olivine grain size of $100 \mu \mathrm{m}$ based on kinetic laws determined with experiments on powders. The main parameter controlling reaction rate is the fluid composition. The slower rates are measured in experiments using pure water $\left(\tau=2.10^{8} s\right)($ Malvoisin et al. 2012a) whereas the faster rates are measured with 270 alkaline fluids $\left(\tau=10^{7} s\right)$ (Lafay et al. 2012). We use in the following $\tau$ values comprised between $10^{7} \mathrm{~s}$ and $10^{9} \mathrm{~s}$. These estimates of parameters are used to determine $D a$ and $D e$ values ranging from $10^{-1.15}$ to $10^{3.8}$ and $10^{-1.5}$ to $10^{5}$, respectively. For each system of equations, we perform simulations with the two assumptions of constant solid volume (i) and constant total pressure (ii). We

275 run 930 simulations at various $D e$ and $D a$ values for each pair of solved equations/assumption ( $4 \times 930$ simulations in total). The simulations are stopped when the minimum porosity is below $10^{-15}$ or when the maximum extent of reaction is above $99 \%$.

\subsection{Porosity clogging with the classical approach}

We first use the system of equations 9 to model serpentinisation. Reaction leads to fluid pressure decrease due to water consumption by reaction. This 

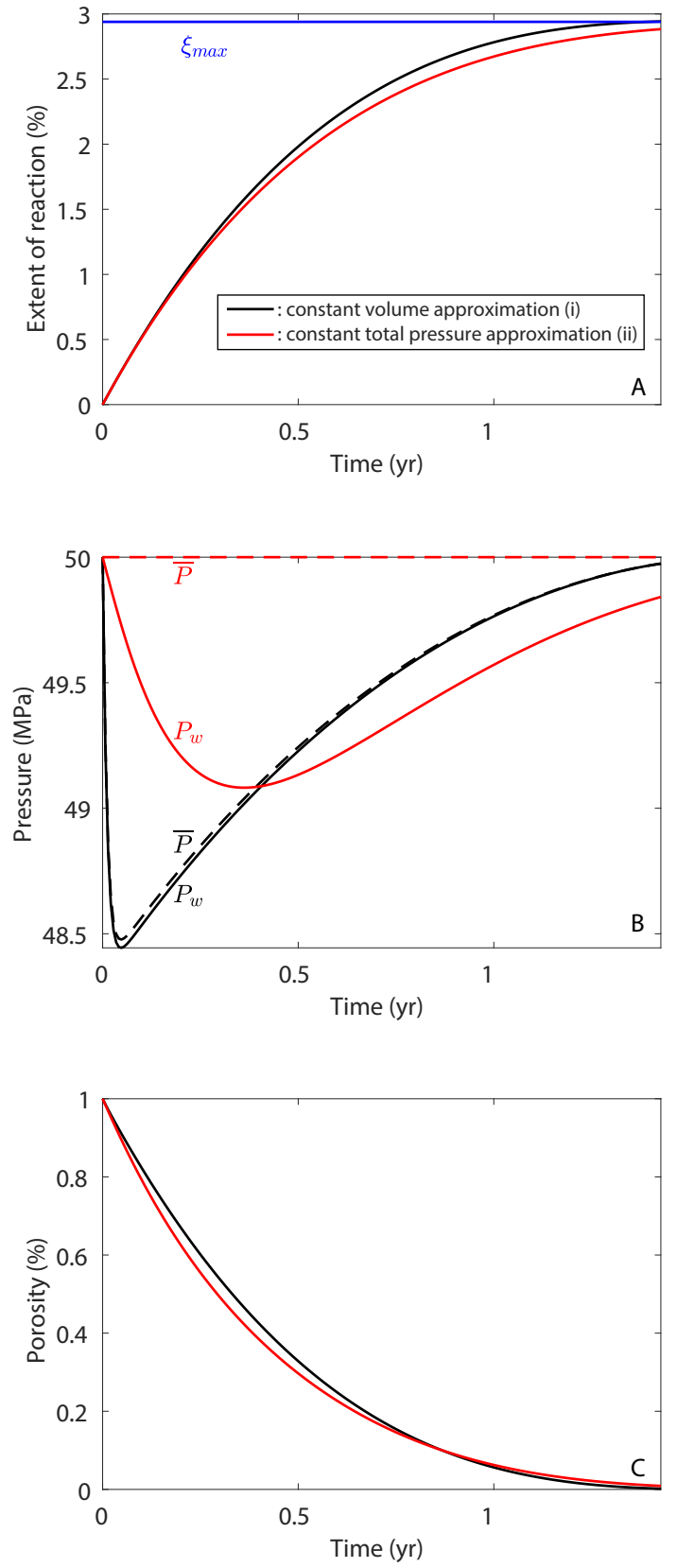

Figure 2: Results of simulations using the classical approach (equations 7 and 9 . The evolutions with time of extent of reaction (A), fluid pressure (plain line) and total pressure (dashed line) (B), and porosity (C) are displayed. The models displayed with black and red lines consider a constant volume (i) or a constant total pressure (ii) for closing the system of equations, respectively. The blue line in subpanel A corresponds to the maximum extent of reaction predicted for a non-deforming solid matrix ( $\xi_{\max }$; see text for details). The models are run with $k_{\phi}=10^{-19} \mathrm{~m}^{2}, L=10 \mathrm{~m}, \tau=5.10^{7} \mathrm{~s}$ and $\eta_{\phi}=10^{18}$ Pa.s $(\mathrm{De}=3 ; \mathrm{Da}=14)$ 
decrease highly depends on the De and Da numbers used in the simulations when a constant solid volume (i) is assumed (Figure S2B). At high De and low $\mathrm{Da}, P_{w}$ variations are limited to several megapascals (Figure 2) whereas, at low De and high Da, it can reach several tens of megapascals (Figure S2). The water vapor pressure at $200{ }^{\circ} \mathrm{C}(1.6 \mathrm{MPa})$ can even be achieved. The model does not take into account the effect of vaporisation on density evolution and is thus not relevant for fluid pressures below the water vapor pressure. The fluid pressure decrease is limited to less than $3 \mathrm{MPa}$ when a constant total pressure (ii) is used (Figures 2 B and S3 B). The difference between fluid and total pressure indeed drives viscoelastic compaction, limiting fluid pressure variations relative to total pressure. For all the parameter values investigated here, the model predicts a similar decrease of the reaction rate due to porosity clogging by reaction products (Figures $2 \mathrm{~A}, \mathrm{~S} 2 \mathrm{~A}$ and $\mathrm{S} 3 \mathrm{~A}$ ). The reaction ultimately stops when the porosity and the reactive surface area are zero. The maximum extent of reaction reached in the simulations is $\xi_{\max }=3 \%$. The maximum reaction extent can be predicted by integrating the porosity evolution equation in the system of equation 9 when assuming no deformation and reaction thus limited by the free space initially available $\left(\phi_{0}\right)$. The obtained expression is $300 \xi_{\max }=\frac{\phi_{0}}{X_{\text {seq }}\left(1+\beta_{s r}\right)}$ giving a value of $2.94 \%$ for $\phi_{0}=0.01$, consistent with the model predictions. This expression of $\xi_{\max }$ also provides the minimum initial porosity required to completely serpentinise a rock with the model based on equations 9. We calculate here a minimum initial porosity of $34 \%$.

\subsection{Complete serpentinisation with reaction-induced deformation}

The results of numerical modelling with equations 13 significantly depend on the assumption used for closing the system of equations. When assuming a constant solid volume (i), the evolutions of extent of reaction and porosity are similar to the classical approach. The extent of reaction reaches a maximum close to $\xi_{\max }$ (Figures $3 \mathrm{~A}$ and $\mathrm{S} 4 \mathrm{~A}$ ) as the porosity decreases to become zero (Figures $3 \mathrm{C}$ ). The mechanism of porosity decrease is however different since it is due to mechanical closure here whereas it is due to the precipitation of reaction products in the simulations performed with the classical approach. The driving force for viscoelastic compaction is the total pressure increase as a result of solid volume increase during reaction (Figure $3 \mathrm{C}$ ). We calculate a maximum total pressure increase of $14 \mathrm{MPa}$ along a segment spanning from $D a=10$ and $D e=10^{1.5}$ to $D a=10^{4}$ and $D e=10^{3}$ in Figure S4 B. This indicates that reaction-induced pressure increase is favored by a high reaction rate, a high viscosity and/or a low effective compressibility.

We observe two types of behaviour when assuming a constant total pressure (ii). At high $D a$ and low $D e$, porosity clogging occurs as a a result of mechanical compaction as observed with assumption (i) (Figure S5). The final extent of reaction is close to $\xi_{\max }$. At low $D a$ and high $D e$, the porosity and the fluid pressure only change during simulation by less than $0.5 \%$ and several megapascals, respectively (Figure $3 \mathrm{E}$ and $\mathrm{F}$ ). Fluid pathways are thus preserved, and the extent of reaction reaches $100 \%$ (Figures $3 \mathrm{D}$ and S5 A). The solid volume 

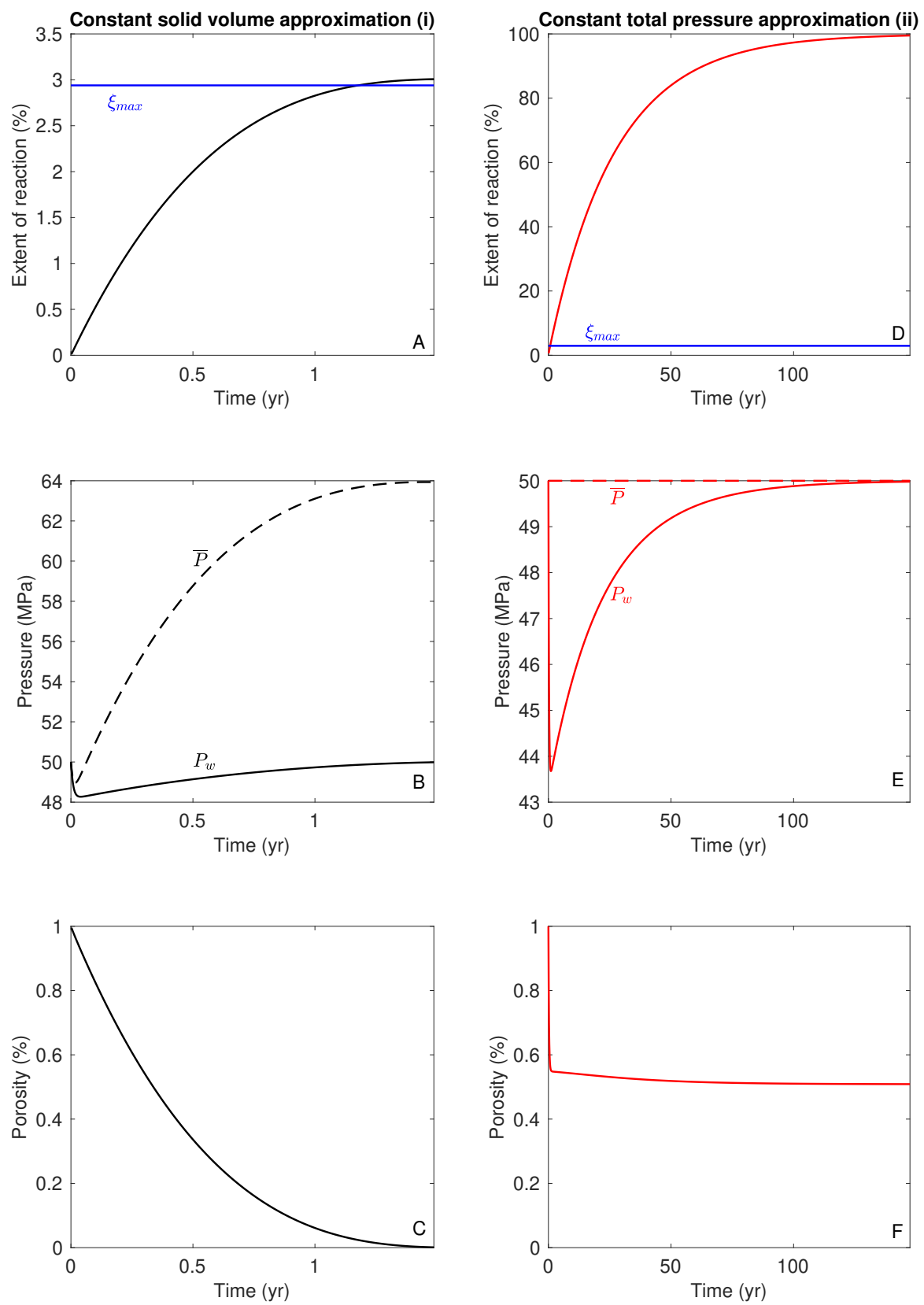

Figure 3: Results of the reaction-induced deformation numerical model (equations 7 and 13 . when assuming a constant solid volume (A, B and C) or a constant total pressure (D, E and $\mathrm{F})$. The evolutions with time of extent of reaction (A and D), fluid pressure (plain line) and total pressure (dashed line) (B and $\mathrm{E}$ ), and porosity $(\mathrm{C}$ and $\mathrm{F}$ ) are displayed. The blue line in subpanels $\mathrm{A}$ and $\mathrm{D}$ corresponds to the maximum extent of reaction predicted for a nondeforming solid matrix $\left(\xi_{\max }\right.$; see text for details). The model is run with $k_{\phi}=10^{-19} \mathrm{~m}^{2}$, $L=10 \mathrm{~m}, \tau=5.10^{7} \mathrm{~s}$ and $\eta_{\phi}=10^{18} \mathrm{~Pa} . \mathrm{s}$ 
increase is accommodated by the expansion of the rock matrix. As porosity is rather constant during reaction, the duration of the reaction only depends on $\tau$ and $\phi_{0}$ according to equation 7 . The simulation displayed in Figure 3 reaches for example completion after approximately $150 \mathrm{yr}$.

\section{Discussion and conclusion}

Several numerical approaches have been used to model serpentinisation. Most of them investigate the influence of positive volume increase during reaction on fluid pathways formation (Rudge et al., 2010, Ulven et al., 2014, Malvoisin et al., 2017, Zhang et al., 2019). Nevertheless, the most complete

335 models coupling reaction, stress variation, fluid flow and permeability do not produce complete serpentinisation in the entire rock (Evans et al., 2020). Reactive transport models such as TOUGHREACT ( $\mathrm{Xu}$ et al., 2011) also fail to reach high extents of reaction while the solid volume increases during reaction (Paukert, 2014). All these models are based on the same principle as the clas340 sical approach detailed here in section 2.1 with a decoupling of reaction and deformation. Positive volume increase can only be accommodated by precipitation in the pores. Mass transfer is assumed to occur at least between the surface of the reacting primary minerals and the pores. The fluid pathways are rapidly clogged, leading to the stop of the reaction if the initial porosity is below $\sim 30 \%$

345 (Figure 2). The consumption of fluid by the reaction leads to a decrease in fluid pressure which can reach several tens of megapascals (Figure 2). Evans et al. (2020) predict a similar behaviour but they consider an additional mechanical feedback between fluid pressure variation and tensile failure. This latter coupling allows porosity to be generated in the fractures as fluid pressure decreases 350 whereas the model proposed here only allows viscoelastic compaction to occur. However, the generated porosity is not sufficient to reach high extents of reaction outside the cracks (Evans et al., 2020). These model predictions are not consistent with the observations in natural samples in which extents of reaction above $60 \%$ are commonly measured (Oufi, 2002).

355 The observations of Beard et al. (2009), Boudier et al. (2010) and Malvoisin et al. (2020b) indicate that reaction proceeds locally with mass transfer limited to the submicrometric scale. Positive volume change is thus not accommodated by precipitation, probably due to a slow transport of the aqueous species. The only other way to account for positive volume change in a closed system is to 60 12). Deriving the change in porosity with this latter equation (last equation in 13 provides an equation without reactive terms, that is without porosity clogging. The modification of equation 12 thus allows for accommodating positive change in solid volume through reaction-induced deformation rather than

365 precipitation in the pores. We solve the system of equations by considering two extreme cases, either no solid volume change (e.g. volume-controlled) or constant total pressure (e.g. stress-controlled).

Reaction is controlled by deformation in our model. If the rock can freely deform by assuming negligible shear stresses (i.e. stress-controlled simulations 
(ii)), a maximum serpentinisation rate $\left(\dot{\xi}_{\max }\right)$ is estimated since shear deformation can only delay the volumetric expansion. $\dot{\xi}_{\text {max }}$ depends only on $\tau$ and is thus controlled by dissolution and precipitation occurring at the olivine surface (Figures 3 and S5). Complete reaction is achieved in less than $1000 \mathrm{yr}$, in agreement with previous estimates based on experimental data and reaction-induced 375 fracturing modelling (Malvoisin et al. 2017). The rock expands by approximately $50 \%$ with consequences for surface uplift and large scale deformation at mid-ocean ridges and in subduction zones (Germanovich et al., 2012).

If deformation is not allowed (i.e. volume-controlled simulations (i)), the serpentinisation rate is zero and the reaction does not reach completion (Figures 3 and S4)). We refine the estimation of the minimum reaction rate $\left(\dot{\xi}_{\text {min }}\right)$ in the following by considering volumetric expansion associated with tectonic deformation which is the main process of deformation at mid-ocean ridges (Cannat, 1993). Tectonic deformation is partitioned between dilatational and shear strains. Microstructural observations indicate that strain in detachment faults is accommodated by crystal-plastic flow and diffusive mass transfer in multiple shear zones (Schroeder and John, 2004, Boschi et al., 2006). Reaction-softening associated with talc formation promotes shear strain localisation, suggesting that shear deformation accommodates a significant proportion of the deformation. However, this proportion is difficult to quantify since most numerical modof mantle rock exhumation at mid-ocean ridges are incompressible (Behn and Ito, 2008: Bickert et al., 2020). The model developed here is one-dimensional and does not allow for shear deformation to be modelled. Moreover, volume increase during reaction can only be accommodated by expansion. As a result, we only consider dilatational strain in the following by introducing a constant 395 rate of expansion in the model $\left(\nabla_{j} v_{s}^{j}=\epsilon_{V}\right.$ with $\epsilon_{V}$ a constant dilatational strain rate imposed by tectonics). Our model is thus not able to probe all the complex interactions between tectonic deformation and serpentinisation at midocean ridges. However, it allows determining the conditions for which tectonic expansion is slower than volume increase induced by dissolution/precipitation 400 (tectonic-controlled versus dissolution/precipitation-controlled rate).

Simulations performed with several imposed dilatational strain rates indicate that the serpentinisation rate is first equal to a high rate controlled by dissolution and precipitation and rapidly decreases with time (Figure 44). For $\epsilon_{V}<10^{-13} s^{-1}$ and $\eta_{\phi}=10^{18}$ Pa.s, the reaction rate decreases to zero as a result of viscoelastic compaction associated with reaction-induced total pressure increase. For $\epsilon_{V}>10^{-13} s^{-1}$ and $\eta_{\phi}=10^{18} \mathrm{~Pa}$.s, the serpentinisation rate reaches a constant value, indicating, with the formalism adopted in equation 7. that the porosity is constant. The equation for porosity in the system of equations 13 can be solved for a constant dilatational strain rate and a constant ${ }_{410}$ porosity to obtain an equation for the minimum serpentinisation rate:

$$
\dot{\xi}_{\text {min }}=-\frac{\beta_{s}^{\prime}\left(1-X_{s}\right)}{X_{\text {seq }}\left(1+\beta_{s r}\right)\left(\beta_{d}(1-\phi)-\beta_{s}^{\prime}\right)} \frac{\bar{P}-P_{w}}{(1-\phi) \eta_{\phi}}+\frac{\epsilon_{V}\left(1-X_{s}\right)}{X_{s e q}\left(1+\beta_{s r}\right)}
$$

The analytical solution provided by equation 14 fits well with the constant 


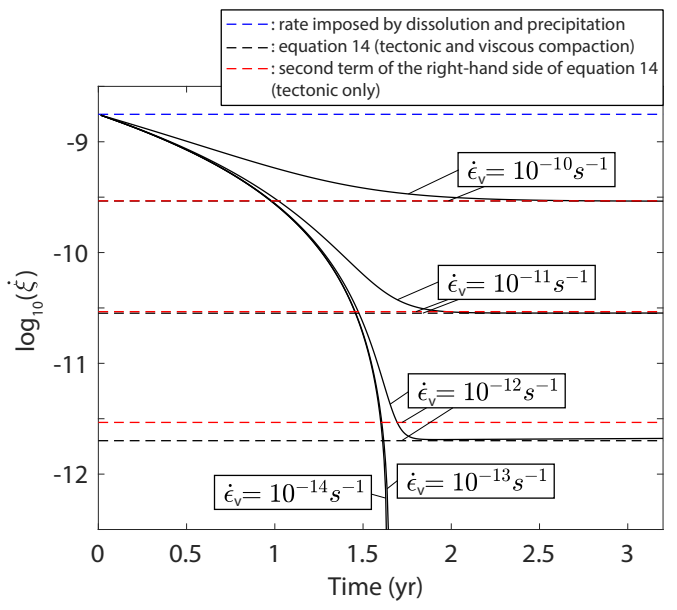

Figure 4: Serpentinisation rate $(\dot{\xi})$ as a function of time for the model considering reactioninduced deformation and an imposed tectonic expansion. The plain black lines corresponds to five simulations performed with $k_{\phi}=10^{-19} \mathrm{~m}^{2}, L=10 \mathrm{~m}, \tau=5.10^{7} \mathrm{~s}, \eta_{\phi}=10^{18} \mathrm{~Pa} . \mathrm{s}$, and at the indicated dilatational strain rates $\left(\epsilon_{V}\right)$. The blue dashed line corresponds to the rate imposed by dissolution and precipitation. The black dashed lines corresponds to the rate calculated with equation 14 considering tectonic deformation and viscous compaction. The red dashed lines corresponds to the rate associated with tectonic deformation only and calculated with the second term of right-hand side of equation 14 Note that the serpentinisation rate tends towards the rate imposed by tectonic deformation for $\epsilon_{V}>10^{-13} s^{-1}$.

reaction rate achieved in the numerical simulations (Figure 4), showing that the minimum serpentinisation rate is controlled by a competition between viscous compaction (first term of right-hand side of equation 14) and tectonic expansion (second term of right-hand side of equation 14). Figure 5 provides the time necessary to reach an extent of reaction of $80 \%$ as a function of dilatational strain rate and viscosity (see Supplementary material for details). At low viscosity and low strain rate, reaction does not reach completion as viscous compaction dominates. At moderate to high viscosity and $\epsilon_{V}<3.10^{-10} \mathrm{~s}^{-1}$, the minimum ${ }_{420}$ serpentinisation rate is controlled by tectonic deformation. The time to reach $80 \%$ of reaction linearly decreases with strain rate according to the second term of right-hand side of equation 14. It is in the order of millions or thousands of years for $\epsilon_{V}=10^{-13} s^{-1}$ and $\epsilon_{V}=10^{-10} s^{-1}$, respectively. At $\epsilon_{V}>3.10^{-10} s^{-1}$, the serpentinisation rate calculated with equation 14 is higher than the rate ${ }_{425}$ calculated with equation 7, suggesting that serpentinisation rate is controlled by dissolution and precipitation at the olivine surface.

Estimating if serpentinisation is controlled by reaction-induced deformation or by tectonics is essential to determine if $\dot{\xi}_{\max }$ or $\dot{\xi}_{\min }$ should be used to model serpentinisation at large scale. Reaction-induced deformation can only occur if the pressure generated during volume expansion is sufficient to induce deformation. The maximum total pressure increase $\left(\Delta \bar{P}_{\max }\right)$ can be derived 


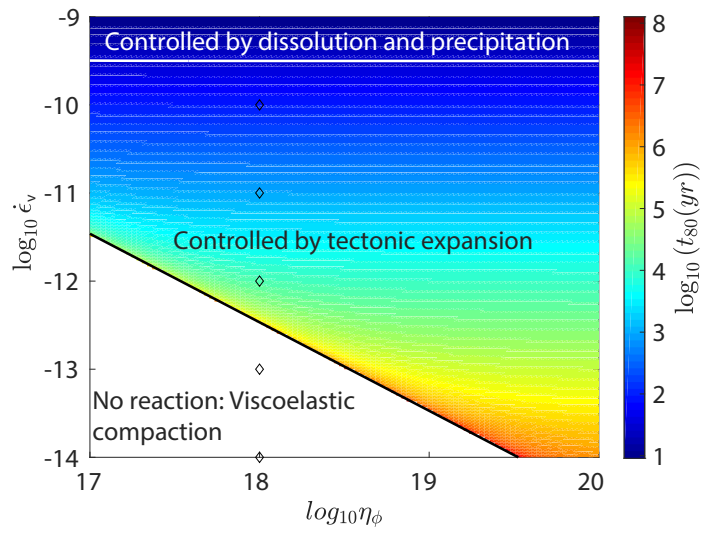

Figure 5: Time necessary to reach $80 \%$ of extent of reaction ( $t_{80}$ in years) as a function of viscosity $\left(\eta_{\phi}\right)$ and dilatational strain rate $\left(\epsilon_{V}\right) . t_{80}$ is calculated with equation 14 Three domains can be distinguished: a domain with no reaction due to viscous compaction leading to fluid pathways clogging, tectonic-controlled domain in which the serpentinisation rate can be expressed with the second term of the right-handed side of equation 14 and a dissolutionand precipitation controlled domain in which the rate determined with equation 14 is faster than the one determined with equation 7

from equation 13 as:

$$
\Delta \bar{P}_{\max }=-\frac{1+\beta_{s r}}{\beta_{d}} \log \left(1-\xi X_{\text {seq }}\right)
$$

Its values for $\xi_{\max }$ and $\xi=1$ are $14 \mathrm{MPa}$ and $\sim 500 \mathrm{MPa}$, respectively, in good agreement with the maximum value calculated in the volume-controlled simulations (14 MPa at $\xi_{\max }$; Figure S4). Pressure increase during precipitation (i.e. crystallisation pressure; $\Delta P_{c}$ ) has been reported in experiments (Correns, 1949). It is generally calculated in excess of the confining pressure as (Kelemen and Hirth, 2012):

$$
\Delta P_{c}=\frac{R T}{V_{m}} \log \Omega
$$

where $\Omega$ is the supersaturation in a thin fluid film where precipitation occurs, $R$ is the gas constant and $V_{m}$ is the molar volume of the precipitating crystal. $\Delta P_{c}$ values calculated for the serpentinisation reaction can exceed $300 \mathrm{MPa}$ (Kelemen and Hirth, 2012), close to the value of $\Delta \bar{P}_{\max }$ at $\xi=1$. However, equations 15 and 16 are based on different approaches since $\Delta \bar{P}_{\text {max }}$ expression considers elastic deformation and depends on the extent of reaction whereas $\Delta P_{c}$

445 equation is based on thermodynamic disequilibrium between the fluid and the solid and requires the fluid to be significantly supersaturated with respect to the precipitating mineral. Experiments of stress monitoring during hydration show that the reaction-induced pressure increase depends on the extent of reaction, that fluid pathways can shut-down as a result of reaction-induced stress, and that the generated overpressures are generally one order of magnitude smaller 
than the one calculated with equation 16 (Wolterbeek et al., 2018, Skarbek et al., 2018). The predictions of our model are in agreement with these results with progressive pressure build-up during reaction, compaction and a relatively small total pressure increase (Figure S4). This suggests that equations 13 are a good alternative to crystallisation pressure calculation based on fluid composition (equation 16), particularly when the supersaturation of the solution is difficult to estimate or when other processes such as mechanical compaction have to be considered. Moreover, it indicates that, for the investigated parameters, the overpressure generated during reaction does not exceed $14 \mathrm{MPa}$ due to viscous 460 compaction (Figure S4). This value is below the yield stress for serpentinised peridotites in compression (Escartín et al., 2001). Our model thus predicts a limited driving force for reaction-induced deformation, which could thus only occur in the first several hundreds of metres below the surface. Figure 5 indicates that serpentinisation may be mainly controlled by tectonic deformation for dilatational strain rates below $3.10^{-10} s^{-1}$ at mid-ocean ridges. This statement is in agreement with the extensive serpentinisation observed near detachments faults (Rouméjon et al., 2015). Moreover, it validates the approach used in some tectonic models (Bickert et al. 2020) in which serpentinisation rate is related to the strain rate. However, one should keep in mind that shear deformation is 470 not taken into account in Figure 5. We indeed use a constant dilatational strain rate that differs from the shear strain rate computed in previous simulations of mid-ocean ridge processes (Bickert et al., 2020). As a result, we do not capture the potential evolution of strain rate during reaction possibly leading to the switch from one controlling mechanism to another. An accurate modelling 475 of the effect of tectonic deformation on serpentinisation rate would require to determine the extent of strain partitioning during exhumation. This should be achieved in the future by solving for the conservation of total momentum in two or three dimensions and by implementing equation 14 in a compressible code. In addition, the model could be improved by considering aqueous species 480 in the fluid to compute the additional thermodynamic force potentially driving stress build-up (equation 16). Viscous compaction is also modelled here with a formalism derived for macropores (Yarushina and Podladchikov, 2015). However, the nanopores preserved during reaction (Tutolo et al., 2016) may behave differently leading to a different evolution of the porosity through time.

The numerical approach proposed here is a critical leap forward in reactive transport modelling since it allows for complete reaction without porosity clogging. Serpentinisation but also other hydration and carbonation reactions inducing a positive change in solid volume can be modelled with the approach proposed here. As a first step, we investigate the volume-controlled and stresscontrolled cases but, as shown above, implementing shear stresses will be required in the future to produce quantitative prediction relevant for natural systems. Another improvement of the model concerns the implementation of gas formation (hydrogen and steam). The reaction indeed consumes water, decreasing the fluid pressure to a level sufficient to produce gases at high $D a$ and low

${ }_{495} D e$ values (Figures S4 B). Vaporisation will in turn significantly modify the fluid density and is thus coupled to fluid pressure evolution. Finally, it would be in- 
teresting to distinguish between nano- and macropores in the model. Tutolo et al. (2016) indeed show that nanopores are preserved during serpentinisation whereas macropores can potentially be filled by an assemblage of reaction products and nanopores. This aspect should be considered to accurately model the evolution of the hydraulic properties during reaction and reproduce the evolution of permeability observed in experiments of serpentinisation (Godard et al. 2013, Farough et al., 2015).

\section{Acknowledgements}

B.M. acknowledges support from the Swiss National Science Foundation (Grant No. PZ00P2_168083). Y.P. and A.M. were supported by the Russian Ministry of Science and Higher Education (project No. 075-15-2019-1890). We thank Luc Lavier and Lars Rüpke for their thoughtful comments and JeanPhilippe Avouac for editorial handling. B.M. had the idea for the reactioninduced swelling approach aboard Chikyu during the Phase 2 Shipboard Science Party of the Oman Drilling Project. He thanks the members of this Science Party for the stimulating atmosphere aboard.

\section{References}

Balashov, V.N., Yardley, B.W.D., 1998. Modeling metamorphic fluid flow with reaction-compaction-permeability feedbacks. American Journal of

1) Science 298, 441-470. URL: http://www.geology.yale.edu/journals/ Ajs.html/http://www.ajsonline.org/cgi/doi/10.2475/ajs.298.6.441, doi:10.2475/ajs.298.6.441.

Bayrakci, G., Minshull, T.A., Sawyer, D.S., Reston, T.J., Klaeschen, D., Papenberg, C., Ranero, C., Bull, J.M., Davy, R.G., Shillington, D.J., PerezGussinye, M., Morgan, J.K., 2016. Fault-controlled hydration of the upper mantle during continental rifting. Nature Geoscience 9, 384-388. URL: WwW.nature.com/naturegeoscience, doi:10.1038/ngeo2671.

Beard, J.S., Frost, B.R., Fryer, P., McCaig, A., Searle, R., Ildefonse, B., Zinin, P., Sharma, S.K., 2009. Onset and progression of serpentinization and magnetite formation in Olivine-rich troctolite from IODP hole U1309D. Journal of Petrology 50, 387-403. doi:10.1093/petrology/egp004.

Behn, M.D., Ito, G., 2008. Magmatic and tectonic extension at mid-ocean ridges: 1. Controls on fault characteristics. Geochemistry, Geophysics,

Geosystems 9, n/a-n/a. URL: https://agupubs.onlinelibrary.

10 wiley.com/doi/full/10.1029/2008GC001965https://agupubs .

onlinelibrary.wiley.com/doi/abs/10.1029/2008GC001965https:

1//agupubs.onlinelibrary.wiley.com/doi/10.1029/2008GC001965http:

//doi.wiley.com/10.1029/2008GC001965, doi:10.1029/2008GC001965. 
Connolly, J., 2005. Computation of phase equilibria by linear programming: A tool for geodynamic modeling and its application to subduction zone decar-

n bonation. Earth and Planetary Science Letters 236, 524-541. URL: http:

//linkinghub.elsevier.com/retrieve/pii/S0012821X05002839https:

565 //linkinghub.elsevier.com/retrieve/pii/S0012821X05002839 doi:10.1016/j.epsl.2005.04.033.

Correns, C.W., 1949. Growth and dissolution of crystals under linear presnure. Discussions of the Faraday Society 5, 267. URL: http://pubs.

1. rsc.org/en/content/articlehtml/1949/df/df9490500267, doi 10.1039/ 570

Delescluse, M., Chamot-Rooke, N., 2008. Serpentinization pulse in the actively deforming Central Indian Basin. Earth and Planetary Science Letters 276, 140-151. URL: http://linkinghub.elsevier.com/retrieve/pii/ S0012821X08005979https://linkinghub.elsevier.com/retrieve/pii/ S0012821X08005979, doi $10.1016 / j \cdot$ epsl.2008.09.017. 
Demartin, B., Hirth, G., Evans, B., 2004. Experimental constraints on thermal cracking of peridotite at oceanic spreading centers, in: Geophysical Monograph Series. Blackwell Publishing Ltd. volume 148, pp. 167-185. URL: http://doi.wiley.com/10.1029/148GM07, doi:10.1029/148GM07.

Emmanuel, S., Berkowitz, B., 2006. Suppression and stimulation of seafloor hydrothermal convection by exothermic mineral hydration. Earth and Planetary Science Letters 243, 657-668. doi:10.1016/j.epsl.2006.01.028.

Escartín, J., Hirth, G., Evans, B., 1997. Effects of serpentinization on the lithospheric strength and the style of normal faulting at slow-spreading ridges. Earth and Planetary Science Letters 151,

181-189. URL: http://www.sciencedirect.com/science/article/pii/ S0012821X9781847X, doi 10.1016/S0012-821X(97)81847-X.

Escartín, J., Hirth, G., Evans, B., 2001. Strength of slightly serpentinized peridotites: Implications for the tectonics of oceanic lithosphere. Geology 29, 1023-1026. doi 10.1130/0091-7613(2001) 029<1023: SOSSPI >2.0.CD

Escartín, J., Smith, D.K., Cann, J., Schouten, H., Langmuir, C.H., Escrig, S., 2008. Central role of detachment faults in accretion of slow-spreading oceanic lithosphere. Nature 455, 790-794. URL: https://www.nature.com/ articles/nature07333, doi:10.1038/nature07333.

Evans, B.W., 1977. Metamorphism of Alpine Peridotite and Serpentinite. Ana nual Review of Earth and Planetary Sciences 5, 397-447. doi 10.1146/ annurev.ea.05.050177.002145

Evans, O., Spiegelman, M., Kelemen, P.B., 2020. Phase-Field Modeling of Reaction-Driven Cracking: Determining Conditions for Extensive Olivine Serpentinization. Journal of Geophysical Research: Solid

Earth 125. URL: https://onlinelibrary.wiley.com/doi/abs/10.1029/ 2019JB018614, doi:10.1029/2019JB018614.

Farough, A., Moore, D.E., Lockner, D.A., Lowell, R.P., 2015. Evolution of fracture permeability of ultramafic rocks undergoing serpentinization at hy605 drothermal conditions : An experimental study. Geochemistry, Geophysics, Geosystems 16, 1-12. doi:10.1002/2015GC005973. Received.

Fletcher, R.C., Merino, E., 2001. Mineral growth in rocks: Kineticrheological models of replacement, vein formation, and syntectonic crystal-

口 lization. Geochimica et Cosmochimica Acta 65, 3733-3748. doi 10.1016/ 610 S0016-7037(01)00726-8.

Germanovich, L.N., Genc, G., Lowell, R.P., Rona, P.a., 2012. Deformation and surface uplift associated with serpentinization at mid-ocean ridges and subduction zones. Journal of Geophysical Research 117, B07103. URL: http: //doi.wiley.com/10.1029/2012JB009372, doi:10.1029/2012JB009372. 

dration of mantle lithosphere at ridges: A reactive-percolation experiment. Earth and Planetary Science Letters 371-372, 92-102. URL: http:

//linkinghub.elsevier.com/retrieve/pii/S0012821X13001799, doi:10. 1016/j.epsl.2013.03.052.

Hilairet, N., Reynard, B., Wang, Y., Daniel, I., Merkel, S., Nishiyama, N., Petitgirard, S., 2007. High-Pressure Creep of Serpentine, Interseismic Deformation, and Initiation of Subduction. Science 318, 1910-

1913. URL: http://www.sciencemag.org/cgi/doi/10.1126/science. 1148494 , doi $10.1126 /$ science. 1148494

Iyer, K., Rüpke, L.H., Morgan, J.P., 2010. Feedbacks between mantle hydration and hydrothermal convection at ocean spreading centers. Earth and Planetary Science Letters 296, 34-44. doi:10.1016/j.epsl.2010.04.037.

Jamtveit, B., Putnis, C.V., Malthe-Sørenssen, A., 2009. Reaction induced fracturing during replacement processes. Contributions to Mineralogy and

630 \. Petrology 157, 127-133. URL: http://link.springer.com/article/10. 1007/s00410-008-0324-y, doi 10.1007/s00410-008-0324-y.

Kelemen, P.B., Hirth, G., 2012. Reaction-driven cracking during retrograde metamorphism: Olivine hydration and carbonation. Earth and Planetary

I Science Letters 345-348, 81-89. URL: http://www.sciencedirect.com/ science/article/pii/S0012821X12003020http://dx.doi.org/10.1016/ j.epsl.2012.06.018, doi:10.1016/j.epsl.2012.06.018.

Kelley, C.T., Keyes, D.E., 1998. Convergence Analysis of Pseudo-Transient Continuation. SIAM Journal on Numerical Analysis 35, 508-523. URL:

a http://epubs.siam.org/doi/10.1137/S0036142996304796, doi10.1137/ S0036142996304796.

Kieffer, B., Jové, C.F., Oelkers, E.H., Schott, J., 1999. An experimental study of the reactive surface area of the Fontainebleau sandstone as a function of porosity, permeability, and fluid flow rate. Geochimica et Cosmochimica Acta 63, 3525-3534. doi 10.1016/S0016-7037(99)00191-X.

${ }_{645}$ Klein, F., Le Roux, V., 2020. Quantifying the volume increase and chemical exchange during serpentinization. Geology URL:

https://pubs.geoscienceworld.org/gsa/geology/article/583188/

1. Quantifying-the-volume-increase-and-chemical, doi 10.1130/G47289. 1 .

${ }_{650}$ Lafay, R., Montes-Hernandez, G., Janots, E., Chiriac, R., Findling, N., Toche, F., 2012. Mineral replacement rate of olivine by chrysotile and brucite under high alkaline conditions. Journal of Crystal Growth 347, 6272. URL: http://dx.doi.org/10.1016/j.jcrysgro.2012.02.040 doi:10. 1016/j.jcrysgro.2012.02.040. 
Lichtner, P.C., 1988. The quasi-stationary state approximation to coupled mass transport and fluid-rock interaction in a porous medium. Geochimica et

ם Cosmochimica Acta 52, 143-165. URL: http://linkinghub.elsevier.com/ retrieve/pii/0016703788900634, doi 10.1016/0016-7037(88)90063-4.

Liu, D., Agarwal, R., Li, Y., Yang, S., 2019. Reactive transport modeling of mineral carbonation in unaltered and altered basalts during $\mathrm{CO} 2$ sequestration.

International Journal of Greenhouse Gas Control 85, 109-120. URL: https:

//linkinghub.elsevier.com/retrieve/pii/S1750583618309009, doi:10. 1016/j.ijggc.2019.04.006.

Llana-Fúnez, S., Brodie, K.H., Rutter, E.H., Arkwright, J.C., 2007. Experimental dehydration kinetics of serpentinite using pore volumometry. Journal of

netamorphic Geology 25, 423-438. URL: http://doi.wiley.com/10.1111/ j.1525-1314.2007.00703.x doi $10.1111 / j .1525-1314.2007 .00703 . x$

Macdonald, A., Fyfe, W., 1985. Rate of serpentinization in seafloor environments. Tectonophysics 116, 123-135. URL: https://linkinghub.elsevier.com/retrieve/pii/0040195185902252, doi:10.1016/0040-1951(85) 90225-2.

Malvoisin, B., Austrheim, H., Hetényi, G., Reynes, J., Hermann, J., Baumgartner, L.P., Podladchikov, Y.Y., 2020a. Sustainable densification of the deep crust. Geology 48, 673-677. doi 10.1130/G47201.1.

Malvoisin, B., Brantut, N., Kaczmarek, M.A., 2017. Control of serpentinisation rate by reaction-induced cracking. Earth and Planetary Science Letters

a 476, 143-152. URL: https://linkinghub.elsevier.com/retrieve/pii/ S0012821X17304260, doi $10.1016 / \mathrm{j}$.epsl.2017.07.042.

Malvoisin, B., Brunet, F., Carlut, J., Rouméjon, S., Cannat, M., 2012a. Ser${ }_{680}$ pentinization of oceanic peridotites: 2. Kinetics and processes of San Carlos olivine hydrothermal alteration. Journal of Geophysical Research: Solid Earth 117, n/a-n/a. URL: http://doi.wiley.com/10.1029/2011JB008842, doi:10.1029/2011JB008842.

Malvoisin, B., Carlut, J., Brunet, F., 2012b. Serpentinization of oceanic peri${ }_{685}$ dotites: 1. A high-sensitivity method to monitor magnetite production in hydrothermal experiments. Journal of Geophysical Research: Solid Earth 117. doi $10.1029 / 2011$ JB008612.

Malvoisin, B., Podladchikov, Y.Y.Y., Vrijmoed, J.C.J., 2015. Coupling changes in densities and porosity to fluid pressure variations in reactive porous fluid flow: Local thermodynamic equilibrium. Geochemistry Geophysics Geosys-

tems 16, 1-57. URL: http://doi.wiley.com/10.1002/2015GC006019http:

//onlinelibrary.wiley.com/doi/10.1002/2015GC006019/full, doi:10. 1002/2015GC006019. 
Malvoisin, B., Zhang, C., Müntener, O., Baumgartner, Lukas, P., Kelemen, P.B., Oman Drilling Project Science Party, 2020b. Measurement of volume change and mass transfer during serpentinisation: insights from the Oman Drilling Project. Journal of Geophysical Research: Solid Earth .

Marini, L., 2007. Geological Sequestration of Carbon Dioxide: Thermodynamics, Kinetics, and Reaction Path Modeling, in: Geological Sequestration of Carbon Dioxide: Thermodynamics, Kinetics, and Reaction Path Modeling. Elsevier. volume 11, pp. 319-409. URL: https://books. google.ch/books?hl=fr $\{\&\}$ lr $=\{\&\}$ id=7GpCbfy7oUQC $\{\&\} \circ i=f n d\{\&\} p g=$ PP1 $\{\&\}$ dq=marini+2007+C02+sequestration $\{\&\}$ ots=DNDqYwZfCL $\{\&\}$ sig $=$ (

science/article/pii/S0921319806800268\{\%\}5Cnhttp://books.google. com/books?hl=en, doi $10.1016 /$ S0921-3198(06)80023-2

Martin, B., Fyfe, W., 1970. Some experimental and theoretical observations on the kinetics of hydration reactions with particular reference to serpentinization. Chemical Geology 6, 185-

202. URL: http://www.sciencedirect.com/science/article/pii/ 0009254170900185, doi $10.1016 / 0009-2541(70) 90018-5$.

McCollom, T.M., Seewald, J.S., 2013. Serpentinites, Hydrogen, and Life. El-

(1) ements 9. URL: http://elements.geoscienceworld.org/content/9/2/ 129 .

715 O'Hanley, D.S., 1992. Solution to the volume problem in serpentinization. Geology 20, 705-708. doi $10.1130 / 0091-7613(1992) 020<0705$ : STTVPI>2.3.CO

Omlin, S., Malvoisin, B., Podladchikov, Y.Y., 2017. Pore Fluid Extraction by Reactive Solitary Waves in 3-D. Geophysical Research Letters 44, 9267-

(1) 9275. URL: http://doi.wiley.com/10.1002/2017GL074293, doi 10.1002/ 2017GL074293.

Oufi, O., 2002. Magnetic properties of variably serpentinized abyssal perin dotites. Journal of Geophysical Research 107. URL: http://www.agu.org/ pubs/crossref/2002/2001JB000549.shtml, doi:10.1029/2001JB000549.

Paukert, A., 2014. Mineral Carbonation in Mantle Peridotite of the Samail 725 Ophiolite, Oman : Implications for permanent geological carbon dioxide capture and storage, 166doi $10.7916 /$ D85M63WZ

Plümper, O., Røyne, A., Magrasó, A., Jamtveit, B., 2012. The interface-scale mechanism of reaction-induced fracturing during serpentinization. Geology 40, 1103-1106. doi:10.1130/G33390.1.

730 Ranero, C.R., Phipps Morgan, J., McIntosh, K., Relchert, C., 2003. Bending-related faulting and mantle serpentinization at the Middle Amern ica trench. Nature 425, 367-373. URL: https://pubmed.ncbi.nlm.nih. gov/14508480/, doi:10.1038/nature01961. 
Rouméjon, S., Cannat, M., Agrinier, P., Godard, M., Andreani, M., 2015. Serpentinization and Fluid Pathways in Tectonically Exhumed Peridotites from the Southwest Indian Ridge (62-65 E). Journal of Petrology 56, 703-

734. URL: https://academic.oup.com/petrology/article-lookup/doi/ 10.1093/petrology/egv014 doi:10.1093/petrology/egv014

Rudge, J.F., Kelemen, P.B., Spiegelman, M., 2010. A simple model of reaction-induced cracking applied to serpentinization and carbonation of peridotite. Earth and Planetary Science Letters 291, 215-227. URL: http:

//linkinghub.elsevier.com/retrieve/pii/S0012821X10000452, doi:10. 1016/j.epsl.2010.01.016.

Rüpke, L.H., Hasenclever, J., 2017. Global rates of mantle serpentinization 745 and $\mathrm{H} 2$ production at oceanic transform faults in 3-D geodynamic models.

1 Geophysical Research Letters 44, 6726-6734. URL: http://doi.wiley.com/ 10.1002/2017GL072893, doi 10.1002/2017GL072893.

Russell, M.J., Hall, A.J., Martin, W., 2010. Serpentinization as a source n of energy at the origin of life. Geobiology 8, 355-371. URL: http:

750 I/doi.wiley.com/10.1111/j.1472-4669.2010.00249.x doi $10.1111 / \mathrm{j}$. $1472-4669.2010 .00249 . x$

Schmalholz, S.M., Moulas, E., Plümper, O., Myasnikov, A.V., Podladchikov, Y.Y., 2020. 2D HydroMechanicalChemical modelling of (de)hydration reactions in deforming heterogeneous rock: The periclasebrucite model reaction.

755 Geochemistry, Geophysics, Geosystems URL: https://onlinelibrary. wiley.com/doi/10.1029/2020GC009351, doi:10.1029/2020GC009351.

Schroeder, T., John, B.E., 2004. Strain localization on an oceanic detachment fault system, Atlantis Massif, 30N, Mid-Atlantic Ridge. Geochemistry, Geophysics, Geosystems 5, n/a-n/a. URL: https://agupubs.onlinelibrary. wiley.com/doi/full/10.1029/2004GC000728https://agupubs .

onlinelibrary.wiley.com/doi/abs/10.1029/2004GC000728https:

//agupubs.onlinelibrary.wiley.com/doi/10.1029/2004GC000728http: //doi.wiley.com/10.1029/2004GC000728, doi:10.1029/2004GC000728.

Shimizu, H., Okamoto, A., 2016. The roles of fluid transport and surface reaction in reaction-induced fracturing, with implications for the development of mesh textures in serpentinites. Contributions to Mineralogy and Petrology 171, 73. URL: http://link.springer.com/10.1007/s00410-016-1288-y, doi $10.1007 / \mathrm{s} 00410-016-1288-y$.

Skarbek, R.M., Savage, H.M., Kelemen, P.B., Yancopoulos, D., 2018. Competition Between Crystallization-Induced Expansion and Creep Compaction During Gypsum Formation, and Implications for Serpentinization. Jour-

nal of Geophysical Research: Solid Earth 123, 5372-5393. URL: http: //doi.wiley.com/10.1029/2017JB015369, doi:10.1029/2017JB015369. 
Szitkar, F., Dyment, J., Fouquet, Y., Honsho, C., Horen, H., 2014. The magnetic signature of ultramafic-hosted hydrothermal sites. Geology 42, 715-718. doi:10.1130/G35729.1.

Thayer, T.P., 1966. Serpentinization considered as a constant-volume metasomatic process. The American minerologist 51, 685-710. URL: https://pubs.geoscienceworld.org/msa/ammin/article-abstract/51/ $5-6 / 685 / 540300$.

Tian, M., Ague, J.J., 2014. The impact of porosity waves on crustal reaction progress and $\mathrm{CO} 2$ mass transfer. Earth and Planetary Science Letters 390, 80-92. URL: http://dx.doi.org/10.1016/j.epsl.2013.12.044http:

1//inkinghub.elsevier.com/retrieve/pii/S0012821X13007590 doi:10. 1016/j.epsl.2013.12.044.

Tian, M., Ague, J.J., Chu, X., Baxter, E.F., Dragovic, N., Chamberlain, C.P., Rumble, D., 2018. The Potential for Metamorphic Thermal Pulses to Develop During Compaction-Driven Fluid Flow. Geochemistry, Geophysics, Geosystems 19, 232-256. URL: http://doi.wiley.com/10.1002/2017GC007269, doi:10.1002/2017GC007269.

Tutolo, B.M., Mildner, D.F., Gagnon, C.V., Saar, M.O., Seyfried, W.E., 2016. Nanoscale constraints on porosity generation and fluid flow during serpentinization. Geology 44, 103-106. URL: http://geology.gsapubs.org/content/44/2/103.shorthttps:

//pubs.geoscienceworld.org/geology/article/44/2/103-106/132000 doi:10.1130/G37349.1

Ulven, O., Jamtveit, B., Malthe-Sørenssen, A., 2014. Reaction-driven fracturing of porous rock. Journal of Geophysical Research: Solid Earth 119, 7473-

1 7486. URL: http://doi.wiley.com/10.1002/2014JB011102, doi 10.1002/ 2014JB011102.

Van Avendonk, H.J., Holbrook, W.S., Lizarralde, D., Denyer, P., 2011. Structure and serpentinization of the subducting Cocos plate offshore Nicaragua and Costa Rica. Geochemistry, Geophysics, Geosystems 12.

URL: https://agupubs.onlinelibrary.wiley.com/doi/full/10.1029/

2011GC003592https://agupubs.onlinelibrary.wiley.com/doi/abs/10.

1029/2011GC003592https://agupubs.onlinelibrary.wiley.com/doi/ 10.1029/2011GC003592, doi:10.1029/2011GC003592

Wolterbeek, T.K., van Noort, R., Spiers, C.J., 2018. Reaction-driven casing expansion: potential for wellbore leakage mitigation. Acta Geotechnica 13, 341-366. doi $10.1007 / \mathrm{s} 11440-017-0533-5$.

Xu, T., Spycher, N., Sonnenthal, E., Zhang, G., Zheng, L., Pruess, K., 2011. Toughreact version 2.0: A simulator for subsurface reactive transport under non-isothermal multiphase flow conditions. Computers and Geosciences 37, 763-774. doi:10.1016/j.cageo.2010.10.007. 
815 Yarushina, V.M., Podladchikov, Y.Y., 2015. (De)compaction of porous viscoelastoplastic media: Model formulation. Journal of Geophysical Re-

q search: Solid Earth 120, 4146-4170. URL:http://doi.wiley.com/10.1002/ 2014JB011258, doi:10.1002/2014JB011258.

Zhang, L., Nasika, C., Donzé, F., Zheng, X., Renard, F., Scholtès, L., 2019. Modeling Porosity Evolution Throughout ReactionInduced Fracturing in Rocks With Implications for Serpentinization. Journal of Geophysical Re-

n search: Solid Earth 124, 5708-5733. URL: https://onlinelibrary.wiley. com/doi/abs/10.1029/2018JB016872, doi:10.1029/2018JB016872. 